\title{
Chloroplast phylogenomics and divergence times of Lagerstroemia (Lythraceae)
}

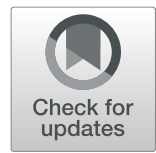

Wenpan Dong ${ }^{1 *}\left(\mathbb{D}\right.$, Chao Xu' ${ }^{2}$, Yanlei Liü ${ }^{2,3}$, Jipu Shi ${ }^{4}$, Wenying $\mathrm{Li}^{5}$ and Zhili Suo ${ }^{2^{*}}$

\begin{abstract}
Background: Crape myrtles, belonging to the genus Lagerstroemia L., have beautiful paniculate inflorescences and are cultivated as important ornamental tree species for landscaping and gardening. However, the phylogenetic relationships within Lagerstroemia have remained unresolved likely caused by limited sampling and the insufficient number of informative sites used in previous studies.

Results: In this study, we sequenced 20 Lagerstroemia chloroplast genomes and combined with 15 existing chloroplast genomes from the genus to investigate the phylogenetic relationships and divergence times within Lagerstroemia. The phylogenetic results indicated that this genus is a monophyletic group containing four clades. Our dating analysis suggested that Lagerstroemia originated in the late Paleocene ( $60 \mathrm{Ma})$ and started to diversify in the middle Miocene. The diversification of most species occurred during the Pleistocene. Four variable loci, $\operatorname{trn} D$ trnY-trnE, rrn16-trnl, ndhF-rp/32-trnL and ycf1, were discovered in the Lagerstroemia chloroplast genomes.

Conclusions: The chloroplast genome information was successfully utilized for molecular characterization of diverse crape myrtle samples. Our results are valuable for the global genetic diversity assessment, conservation and utilization of Lagerstroemia.
\end{abstract}

Keywords: Lagerstroemia, Chloroplast genome, Phylogeny, Divergence time

\section{Background}

Crape myrtles, the genus Lagerstroemia L. (Lythraceae, Myrtales), consisting of approximately 60 species, is mainly naturally distributed in Southern and Eastern Asia and Northern Australia [1-3]. Several species of Lagerstroemia, such as L. floribunda, L. speciosa, L. macrocarpa, L. loudonii, and L. indica, are planted as important ornamental trees. Crape myrtles are known for their longlasting midsummer (more than 100 days) blooms from the tropical to the northern temperate zones. Cultivation of crape myrtles has been carried out for over 2,000 years.

\footnotetext{
*Correspondence: wpdong@bjfu.edu.cn; zlsuo@ibcas.ac.cn

1 Laboratory of Systematic Evolution and Biogeography of Woody Plants,

School of Ecology and Nature Conservation, Beijing Forestry University, 100083 Beijing, China

${ }^{2}$ State Key Laboratory of Systematic and Evolutionary Botany, Institute of Botany, Chinese Academy of Sciences, 100093 Beijing, China

Full list of author information is available at the end of the article
}

There are at least 500 named crape myrtle cultivars available in the U.S., Europe, and Asia [4].

Taxonomically, the genus Lagerstroemia was treated completely by Furtado \& Srisuko [1], and the genus Lagerstroemia was fully revised and classified into three sections (including 53 species), i.e., (1) L. sect. Sibia, (2) L. sect. Adambea, and (3) L. sect. Trichocarpidium. After detailed analyses of the morphological characters and literature, De Wilde and Duyfjes [5] considered that four sections should be divided in Lagerstroemia: (1) L. sect. Lagerstroemia, (2) L. sect. Parviflora, (3) L. sect. Adambea, and (4) L. sect. Trichocarpidium. Several morphological character states have proven to be useful for the determination of Lagerstroemia [2,5], such as the position, size, color, and auricles of flowers; the size, valves, and surface of fruits; the bark of the trunk, and the length of stamens. On this basis, some new taxa in Lagerstroemia have been subsequently described; during

(c) The Author(s). 2021 Open Access This article is licensed under a Creative Commons Attribution 4.0 International License, which permits use, sharing, adaptation, distribution and reproduction in any medium or format, as long as you give appropriate credit to the original author(s) and the source, provide a link to the Creative Commons licence, and indicate if changes were made. The images or other third party material in this article are included in the article's Creative Commons licence, unless indicated otherwise in a credit line to the material. If material is not included in the article's Creative Commons licence and your intended use is not permitted by statutory regulation or exceeds the permitted use, you will need to obtain permission directly from the copyright holder. To view a copy of this licence, visit http://creativecommons.org/licenses/by/4.0/. The Creative Commons Public Domain Dedication waiver (http://creativecommons.org/publicdomain/zero/1.0/) applies to the data made available in this article, unless otherwise stated in a credit line to the data. 
botanical surveys, several new crape myrtle taxa (species and variety) were found in Thailand, Vietnam, Cambodia and Laos [2, 5-7]. However, several plants are still known only from herbarium specimens. There are 115 Lagerstroemia name records in the Plant List database (http://www.theplantlist.org/), and half of the taxonomic status of the name remains unresolved.

A few phylogenetic studies have been conducted on Lagerstroemia, but the interspecific relationships in this group remain controversial. Phylogenetic relationships within Lythraceae based on chloroplast genic regions (rbcL, trnL-F, psaA-ycf3) plus the ITS region showed Lagerstroemia was sister to Duabanga and strongly supported the monophyly of the genus $[8,9]$. The phylogenic relationships within Lagerstroemia have been poorly defined overall using several chloroplast markers and/or the ITS and gene regions of the ubiquitinproteasome system $[10,11]$. The poor phylogenetic resolution in previous studies resulted from limited amounts of DNA sequence data available and the low genetic variation in the chosen molecular markers, likely due to this group's recent origin and rapid radiation.
Chloroplast genomes have proven to be powerful tools for studying phylogenetic relationships in related species because of their small size, high copy number, uniparental inheritance, and conserved gene content and arrangement [12-14]. In recent years, the chloroplast genomes have been sequenced and characterized for species identification and phylogenetic study [15-17]. However, due to sparse taxon sampling in previous studies, the phylogenetic relationships within Lagerstroemia are still unclear.

A robust phylogeny of Lagerstroemia, including more representative species and a large amount of genetic markers, is essential for understanding the evolutionary history, breeding of new cultivars and conservation of crape myrtle germplasm resources. In this study, we sequenced 20 chloroplast genomes of Lagerstroemia samples using next-generation sequencing (NGS). The aims of this study were: (i) to deepen our understanding of chloroplast genome evolution of Lagerstroemia, (ii) to reconstruct the robust phylogenetic relationship of Lagerstroemia, and (iii) to reveal the divergence times involving this genus.

Table 1 Characteristics of newly sequenced plastomes

\begin{tabular}{|c|c|c|c|c|c|c|c|c|c|}
\hline Species & $\begin{array}{l}\text { LSC length } \\
\text { (bp) }\end{array}$ & $\begin{array}{l}\text { IR length } \\
\text { (bp) }\end{array}$ & $\begin{array}{l}\text { SSC length } \\
\text { (bp) }\end{array}$ & $\begin{array}{l}\text { Plastome size } \\
\text { (bp) }\end{array}$ & $\begin{array}{l}\text { GC content } \\
(\%)\end{array}$ & $\begin{array}{l}\text { Gene } \\
\text { number }\end{array}$ & $\begin{array}{l}\text { Protein coding } \\
\text { genes }\end{array}$ & tRNA & $\overline{\text { rRNA }}$ \\
\hline $\begin{array}{l}\text { L. } \\
\text { anhuiensis }\end{array}$ & 84,058 & 25,631 & 16,729 & 152,049 & $37.6 \%$ & 112 & 78 & 30 & 4 \\
\hline $\begin{array}{l}\text { L. } \\
\text { calyculata }\end{array}$ & 84,008 & 25,726 & 16,798 & 152,258 & $37.6 \%$ & 112 & 78 & 30 & 4 \\
\hline L. caudata & 84,025 & 25,625 & 16,919 & 152,194 & $37.6 \%$ & 112 & 78 & 30 & 4 \\
\hline L. excelsa & 84,047 & 25,625 & 16,917 & 152,214 & $37.6 \%$ & 112 & 78 & 30 & 4 \\
\hline L. fauriei & 83,920 & 25,625 & 16,904 & 152,074 & $37.6 \%$ & 112 & 78 & 30 & 4 \\
\hline L. fauriei & 83,919 & 25,625 & 16,904 & 152,073 & $37.6 \%$ & 112 & 78 & 30 & 4 \\
\hline $\begin{array}{l}\text { L. } \\
\text { floribunda }\end{array}$ & 84,000 & 25,716 & 16,793 & 152,225 & $37.7 \%$ & 112 & 78 & 30 & 4 \\
\hline L. glabra & 84,026 & 25,625 & 16,729 & 152,005 & $37.6 \%$ & 112 & 78 & 30 & 4 \\
\hline $\begin{array}{l}\text { L. } \\
\text { guilinensis }\end{array}$ & 83,809 & 25,625 & 16,909 & 151,968 & $37.6 \%$ & 112 & 78 & 30 & 4 \\
\hline L. indica & 84,060 & 25,625 & 16,919 & 152,229 & $37.6 \%$ & 112 & 78 & 30 & 4 \\
\hline L. indica & 84,058 & 25,625 & 16,919 & 152,227 & $37.6 \%$ & 112 & 78 & 30 & 4 \\
\hline $\begin{array}{l}\text { L. } \\
\text { intermedia }\end{array}$ & 83,997 & 25,732 & 16,850 & 152,311 & $37.6 \%$ & 112 & 78 & 30 & 4 \\
\hline L. limii & 83,951 & 25,651 & 16,905 & 152,158 & $37.6 \%$ & 112 & 78 & 30 & 4 \\
\hline L. sp. 01 & 83,982 & 25,726 & 16,800 & 152,234 & $37.7 \%$ & 112 & 78 & 30 & 4 \\
\hline L. sp. 02 & 84,008 & 25,721 & 16,795 & 152,245 & $37.7 \%$ & 112 & 78 & 30 & 4 \\
\hline L. sp. 03 & 84,084 & 25,625 & 16,920 & 152,254 & $37.6 \%$ & 112 & 78 & 30 & 4 \\
\hline L. speciosa & 84,183 & 25,714 & 16,832 & 152,443 & $37.6 \%$ & 112 & 78 & 30 & 4 \\
\hline L. speciosa & 84,188 & 25,804 & 16,833 & 152,629 & $37.6 \%$ & 112 & 78 & 30 & 4 \\
\hline $\begin{array}{l}\text { L. } \\
\text { tomentosa }\end{array}$ & 84,009 & 25,726 & 16,797 & 152,258 & $37.7 \%$ & 112 & 78 & 30 & 4 \\
\hline L. villosa & 84,003 & 25,705 & 16,795 & 152,208 & $37.7 \%$ & 112 & 78 & 30 & 4 \\
\hline
\end{tabular}




\section{Results}

\section{Characteristics of Lagerstroemia chloroplast genomes}

The complete chloroplast genomes of the 20 newly sequenced Lagerstroemia species ranged in length from 151,968 bp (L. guilinensis) to 152,629 bp (L. speciosa) (Table 1). All chloroplast genomes had the four typical conjoined structures, including the LSC and SSC regions separated by two IR regions (Fig. 1). The LSC regions ranged from 83,809 bp (L. guilinensis) to 84,188 bp ( $L$. speciosa) and accounted for $55.20-55.26 \%$ of the total length. The SSC regions varied between 16,729 bp ( $L$. anhuiensis and L. glabra) and 16,920 bp (L. sp. 03) and accounted for $11.00-11.11 \%$ of the total length. The IR regions ranged from $25,625 \mathrm{bp}$ ( $L$. caudata, $L$. excelsa, $L$. fauriei, L. glabra, L. guilinensis, L. indica and L. sp. 03) to $25,804 \mathrm{bp}$ (L. speciosa) and accounted for 16.83$16.91 \%$ of the total length. A total of 112 unique genes were detected in the chloroplast genomes of the 20 Lagerstroemia species, including 78 coding genes, 30 tRNA genes and 4 rRNA genes (Fig. 1; Table 1). GC content ranged from 37.6 to $37.7 \%$. The gene organization, gene order and GC content were highly identical and similar to those of other higher plants (Fig. 1). The overall chloroplast genomic structure, including gene number and gene order, was wellconserved.

\section{cpDNA markers for Lagerstroemia}

The whole chloroplast genome sequences of 35 Lagerstroemia (dataset-3) species were aligned to find the sequence variation. The alignment matrix of the chloroplast genome was 154,185 bp. We identified 2,029 variable sites $(1.316 \%)$, including 1,821 parsimonyinformative sites $(1.181 \%)$ and 205 singleton sites $(0.133 \%)$. The overall sequence divergence estimated by p-distance among the 35 chloroplast genome sequences was 0.0049 . The p-distance ranged from 0.0001 to 0.0080 , and the number of nucleotide substitutions ranged from 22 to 1,215 between species.

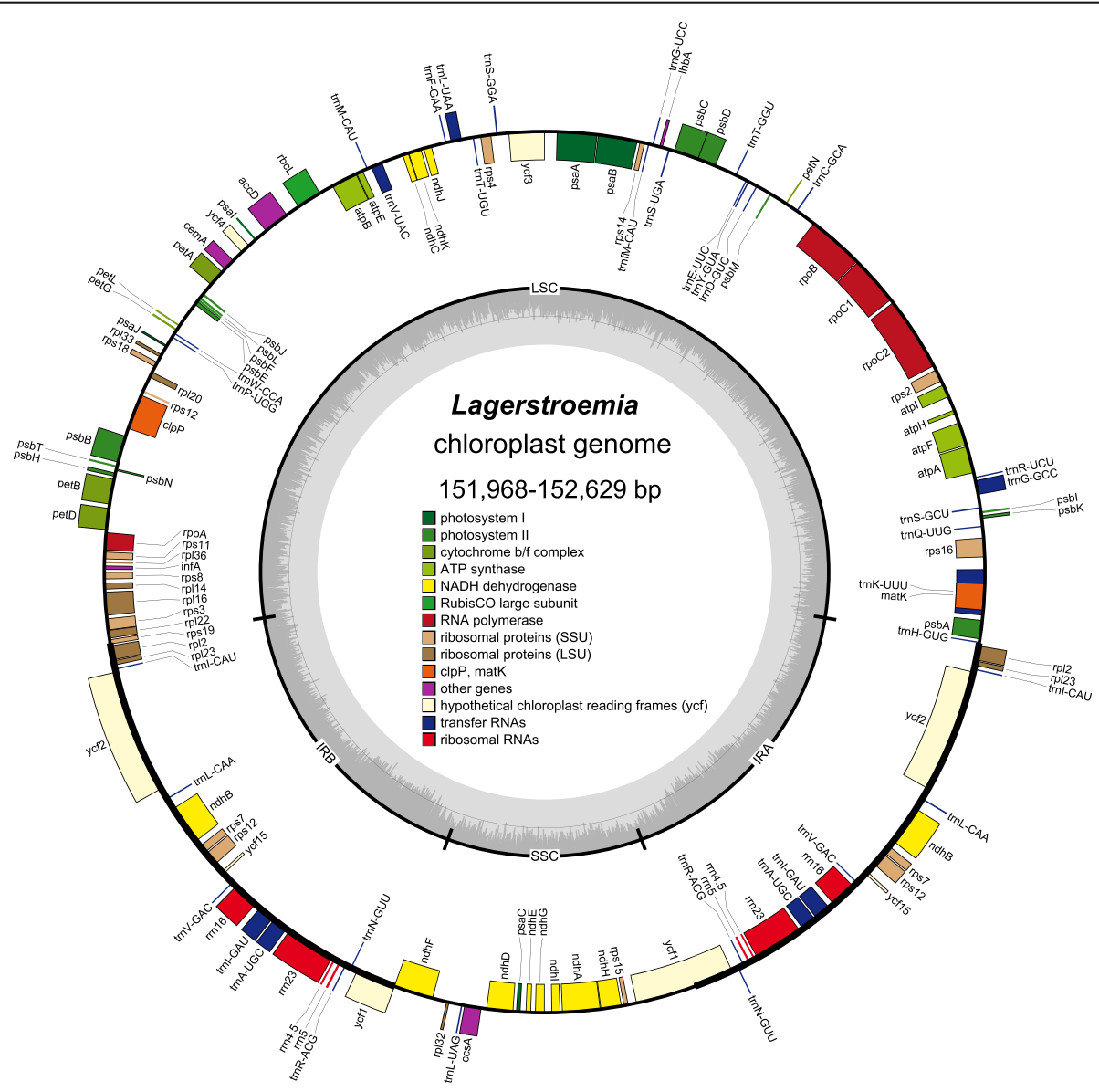

Fig. 1 General chloroplast genome map of Lagerstroemia. Specific sizes for the chloroplast genomes of each species are presented in Table 1. Genes drawn outside of the map circle are transcribed clockwise, while those drawn inside are transcribed counterclockwise. Genes belonging to different functional groups are color-coded. The darker gray in the inner circle corresponds to GC, while the lighter gray corresponds to 
To identify the sequence divergence hotspots, the nucleotide diversity $(\pi)$ value within the slide window of 600 bp was calculated (Fig. 2). The $\pi$ values varied from 0 to 0.0318 , the average pi value was 0.00474 , the IR region exhibited the least nucleotide diversity (0.00285), and the SSC exhibited high divergence (0.01006). Four highly variable regions $(\mathrm{pi}>0.02)$, including trnD-trn $Y$ trnE, rrn16-trnI, ndhF-rpl32-trnL and $y c f 1$, were detected in the Lagerstroemia chloroplast genomes (Fig. 2). Among these regions, $\operatorname{trn} D-\operatorname{trn} Y$-trnE was located in the LSC region, rrn16-trnI was located in the IR region, and $n d h F-r p l 32-t r n L$ and $y c f 1$ were located in the SSC region. We compared the four hypervariable markers and the universal DNA barcodes ( $r b c L$, matK, and $\operatorname{trnH}$ $p s b A$ ) in more detail (Table 2). The number of variable sites of the four markers ranged from 38 (trnD-trnYtrnE) to 56 (rrn16-trnI and ndhF-rpl32-trnL), whereas the universal DNA barcodes had lower divergence. The average nucleotide diversity of the four rapidly evolving regions was 0.01941 , which was 2.5 times higher than that of the universal DNA barcodes. The identified variable markers had higher resolution compared with the three universal markers, based on the ML tree (Figure S1).

\section{Phylogenetic analyses}

Characteristics of the six different datasets used in this study are shown in Table 3. Dataset-3 possesses the most variable and parsimony-information sites, followed by dataset- 2 and dataset- 4 . As expected, dataset- 5 (IR region) had the fewest variable and parsimony-informative sites. Dataset-1 and Dataset-2 strongly supported the monophyly of Lagerstroemia $(\mathrm{BS}=100 / \mathrm{PP}=1.0)$. In this study, analyses based on each dataset revealed four clades in the genus Lagerstroemia. Clade I was sister to Clade II, and Clade III was sister to Clade IV. Clade I included four taxa, namely, $L$. siamica, $L$. intermedia, $L$. speciosa, and $L$. venusta. Only slight differences were found between $L$. speciosa and $L$. venusta. L. siamica was sister to $L$. intermedia. Clade II consists of six taxa: $L$. villosa, $L$. floribunda, $L$. tomentosa, $L$. calyculata, $L$. sp. 01, and $L$. sp. 02. L. villosa was the first divergent species in this clade. Clade III contained three taxa: $L$. fauriei, L. subcostata and L. limii. These three taxa had longer branch on the phylogenetic tree, indicating significant divergence between each other (Fig. 4). Seven taxa are in Clade IV: L. caudata, L. anhuiensis, L. glabra, $L$. excelsa, $L$. guilinensis, $L$. indica, and $L$. sp. 03. $L$. anhuiensis and L. glabra formed a clade and showed short branch in the trees. The topology of the Lagerstroemia samples with high resolution was achieved based on the whole chloroplast genome sequence data (Fig. 4). Figures S2, S3, and S4 show the general decrease in resolution capacity of the topology when either the LSC, IR, or SSC region was used due to the insufficient information.

\section{Divergence time estimate}

Different fossil calibration combinations were computed to investigate the variation of estimation values of the divergence times (Table 4). We focused on the Lagerstroemia stem and crown nodes. The estimated age of stemgroup Lagerstroemia showed a different pattern with younger age estimates when the fossil calibration of Lagerstroemia patelii (>56 Ma, Fig. 5, Note 6) was not included. The Lagerstroemia stem node was $56.34 \pm$ $4.78 \mathrm{Ma}$, and the Lagerstroemia crown node was $31.06 \pm$ $2.82 \mathrm{Ma}$, obtained from the 12 fossil-calibrated analyses (Table 4).

According to the fossil records, Lagerstroemia first appeared in the late Paleocene/early Eocene of the Indian subcontinent [18]. We consider the scenario including all the eight fossil calibrations as the final result (Fig. 5). The stem node of the Lagerstroemia was dated to 60.12 Ma (95\% highest posterior density, HPD: $56.2-$

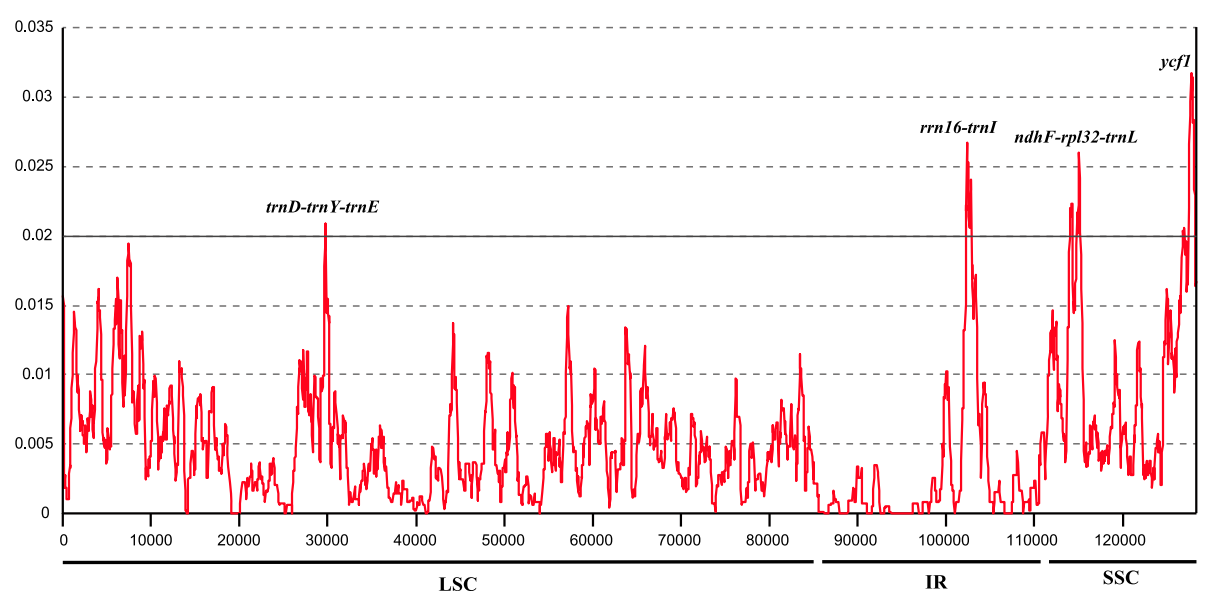

Fig. 2 Sliding window analysis of nucleotide variability (Pi) across 35 complete chloroplast genome sequences of Lagerstroemia 
Table 2 Variability of four hyper-variable markers and the universal chloroplast DNA barcodes ( $r b c L$, matK and trnH-psbA) in Lagerstroemia

\begin{tabular}{|c|c|c|c|c|c|c|}
\hline \multirow[t]{2}{*}{ Markers } & \multirow[t]{2}{*}{ Length } & \multicolumn{2}{|c|}{ Variable sites } & \multicolumn{2}{|c|}{ Information sites } & \multirow[t]{2}{*}{ Nucleotide diversity } \\
\hline & & Numbers & $\%$ & Numbers & $\%$ & \\
\hline $\operatorname{trn} D$-trnY-trnE & 1,051 & 38 & $3.62 \%$ & 36 & $3.43 \%$ & 0.01953 \\
\hline rrn16-trnl & 1,229 & 56 & $4.56 \%$ & 51 & $4.15 \%$ & 0.02040 \\
\hline$n d h F-r p / 32-t r n L$ & 947 & 56 & $5.91 \%$ & 53 & $5.60 \%$ & 0.01848 \\
\hline ycfl & 827 & 41 & $4.96 \%$ & 36 & $4.35 \%$ & 0.01890 \\
\hline Combine four variable markers & 4,054 & 191 & $4.71 \%$ & 176 & $4.34 \%$ & 0.01941 \\
\hline rbcl & 1,428 & 14 & $0.98 \%$ & 14 & $0.98 \%$ & 0.00395 \\
\hline matk & 1,500 & 24 & $1.60 \%$ & 24 & $1.60 \%$ & 0.00636 \\
\hline $\operatorname{trnH}-p s b A$ & 138 & 17 & $12.32 \%$ & 16 & $11.59 \%$ & 0.06441 \\
\hline Combine three universial markers & 3,066 & 55 & $1.79 \%$ & 54 & $1.76 \%$ & 0.00770 \\
\hline
\end{tabular}

66.27 Ma); the crown node of the Lagerstroemia was dated to $31.6 \mathrm{Ma}$ (95 \%HPD: $14.93-49.16 \mathrm{Ma}$ ). Four clades diverged approximately $19.01 \mathrm{Ma}$ (95 \%HPD: $5.95-34.17 \mathrm{Ma})$ and $11.08 \mathrm{Ma}$ (95 \%HPD: $2.58-$ $25.28 \mathrm{Ma}$ ), respectively, between clades I/II and III/IV. Diversification with this genus occurred over a short time period, approximately $5.27 \mathrm{Ma}$.

\section{Discussion}

\section{Informative indicated chloroplast markers for}

\section{Lagerstroemia}

Our results indicate that the mutation patterns of the chloroplast genomes were not uniform. As a whole, the single-copy region possesses a higher divergence than the IR region, and the mutation events of SNPs and indels were not random, but instead were clustered as "mutation hotspots" or "highly variable regions". These results are generally consistent with those from other studies involving chloroplast genomes. Previous phylogenetic studies of Lagerstroemia mainly used the universal chloroplast loci ( $r b c L$, matK, and trnH-psbA) and the ITS, but these did not provide a good resolution of the phylogenetic relationship in this genus [11]. Our results showed that the universal chloroplast markers have low divergence (Table 2), explaining the low resolution in previous studies and highlighting the importance of developing highly divergent markers. In this study, we have identified four highly variable loci: trnD-trnY-trnE, rrn16-trnI, ndhF-rpl32-trnL and ycf1 (Fig. 2). Of these, rrn16-trnI and $y c f 1$ have been considered divergence hotspots by $\mathrm{Xu}$ et al. [15], which compared six Lagerstroemia chloroplast genomes and identified 12 highly variable markers. Previously, trnD-trnY-trnE was less used in plant phylogeny. rrn16-trnI is located in IR regions, which are specific to the Lagerstroemia chloroplast genome. In general, mutation hotspots are rare in the IR region. ndhF-rpl32-trnL included two intergenic regions (ndhF-rpl32 and rpl32-trnL), which showed the highest percentage of variable sites and the highest number of information sites (Table 2). However, there was poly $\mathrm{A} / \mathrm{T}$ structure in this region, which may be regarded as low sequence quality $[19,20]$. The $y c f 1$ locus was the most divergent marker in the Lagerstroemia chloroplast genome (Fig. 2) and has been broadly used for reconstructing plant phylogeny and species identification [21]. Therefore, the lineage-specific, highly variable markers developed in this study will facilitate further phylogeny reconstruction and DNA barcoding of crape myrtle species (Figure S1).

Table 3 Characteristics of the six different data sets

\begin{tabular}{llllll}
\hline Dataset & Composition & $\begin{array}{l}\text { Total number of } \\
\text { characters (bp) }\end{array}$ & $\begin{array}{l}\text { Variable } \\
\text { sites (bp) }\end{array}$ & $\begin{array}{l}\text { Parsimony- } \\
\text { informative sites } \\
\text { (bp) }\end{array}$ & $\begin{array}{l}\text { Singleton } \\
\text { sites (bp) }\end{array}$ \\
\hline 1 & Nucleotide sequences of all 82 genes & 71,424 & 628 & 514 & 114 \\
2 & $\begin{array}{l}\text { Complete chloroplast genome sequences (deletion some } \\
\text { sites according to the outgroups) }\end{array}$ & 151,431 & 1,910 & 1,694 & 216 \\
3 & Complete chloroplast genome sequences & 154,185 & 2,029 & 1,821 & 1,058 \\
4 & LSC & 85,125 & 1,199 & 1,05 & 141 \\
5 & IR & 25,998 & 170 & 156 & 14 \\
6 & SSC & 17,065 & 488 & 434 & 54 \\
\hline
\end{tabular}




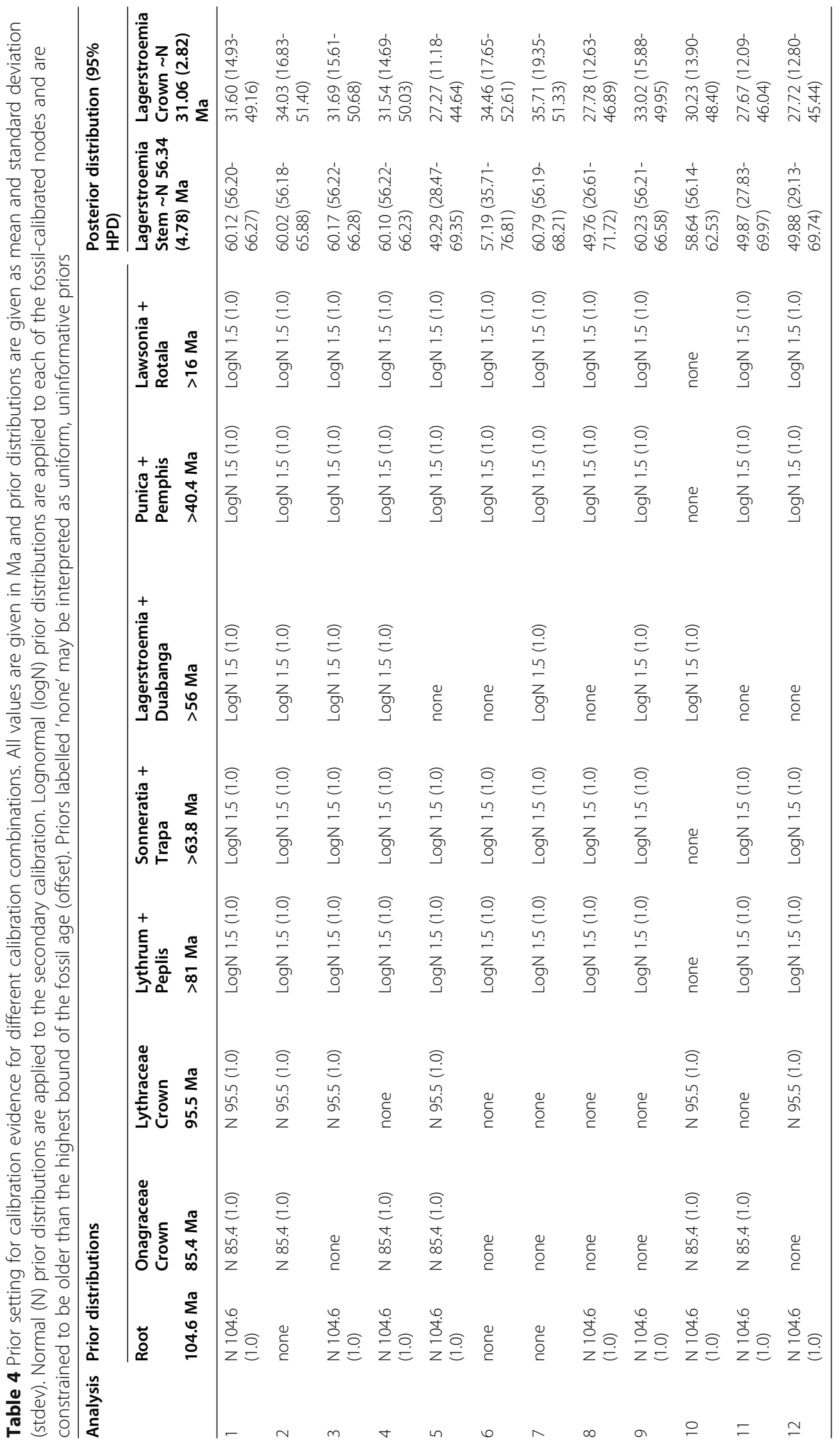




\section{Phylogenetics of Lagerstroemia}

Lagerstroemia was a monophyletic group based on the morphology [1, 3], several chloroplast markers [22] and ITS locus [8]. De Wilde and Duyfjes [5] classified Lagerstroemia into four sections on the basis of the monograph by Furtado \& Srisuko [1]. Several morphological features used for morphological classification of Lagerstroemia in previous reports, such as (1) the number of the ridges on the calyx tube, (2) the number of the ridges is the same as or twice the number of sepals, and (3) glabrous or hairy within the calyx lobes, may be observed in the same clade generated based on the molecular classification. For example, in Clade I, the 6-7 ridges on the calyx tube outside in $L$. venusta is the same as the sepal number, but each of the other two taxa (L. speciosa and $L$. siamica) has 12 ridges on the calyx tube outside, which is twice the number of sepals. Not ridged (L. calyculata), 5-6 ridges (L. villosa), and 12 ridges $(L$. tomentosa) are observed in Clade II. It is difficult to satisfactorily quantify the relationship between the ridge number and the sepal number when no ridge is observed. In Clade IV, L. anhuiensis has hairs within calyx lobes, but it is glabrous within calyx lobes in L. guilingensis, L. caudata, L. glabra and L. indica.
Molecular markers, such as AFLP, SSRs [23], were used to distinguish the cultivars of Lagerstroemia species, such as L. indica, L. subcostata, L. limii and L. fauriei. However, the genetic background of the cultivars was unclear, and these markers were not informative to infer the relationship of those species. The chloroplast genome has become an efficient option for increasing plant phylogenomics at multiple taxonomic levels during the past years [24-29]. We had used the chloroplast genome data to infer phylogenetic relationships of six Lagerstroemia species, and discovered that the chloroplast genome sequences had effective information to infer the phylogeny of this genus [15].

In this study, we recovered a well-supported and species-level relationship of Lagerstroemia using six different chloroplast genome datasets. It provided strong support for the monophyly of Lagerstroemia, sister to Duabanga, and recovered four major clades (Figs. 3 and 4). However, the four clade classifications were different from the morphological classification of the genus [1]. For example, L. speciosa, L. limii, and L. glabra were in the section Adambea, the molecular results showed $L$. speciosa was in the clade $1, L$. limii in the clade 3 , and $L$. glabra in the clade 4, respectively.

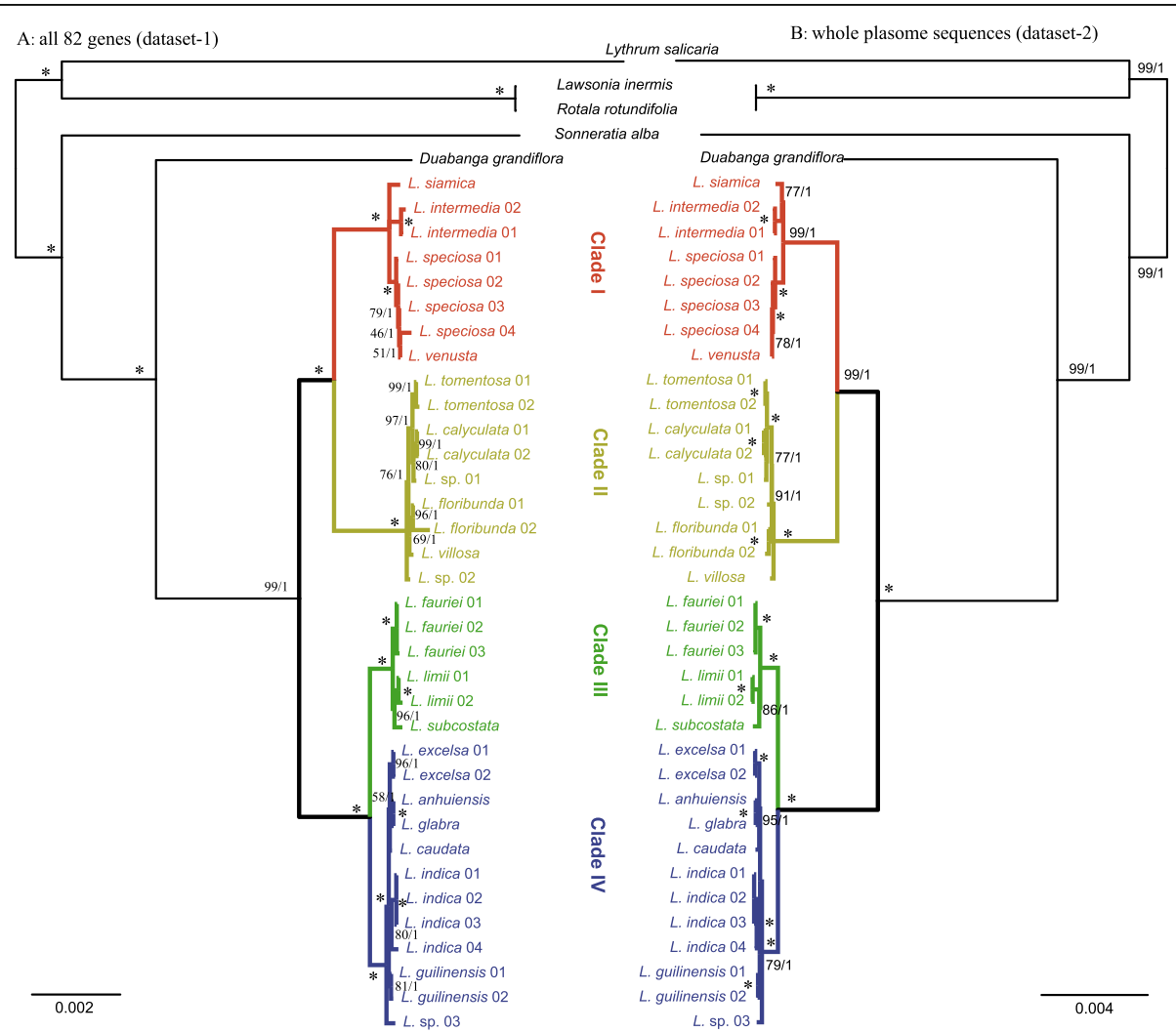

Fig. 3 Molecular phylogeny of Lagerstroemia from ML (maximum likelihood) and BI (Bayesian inference) analyses using different data sets. A Eighty-three coding genes (dataset-1); B. the chloroplast genome sequences (dataset-2). Maximum likelihood bootstrap values (BS) and posterior probabilities (PP) are shown at nodes. Branches with * indicate 100\% BS and a PP of 1.0 


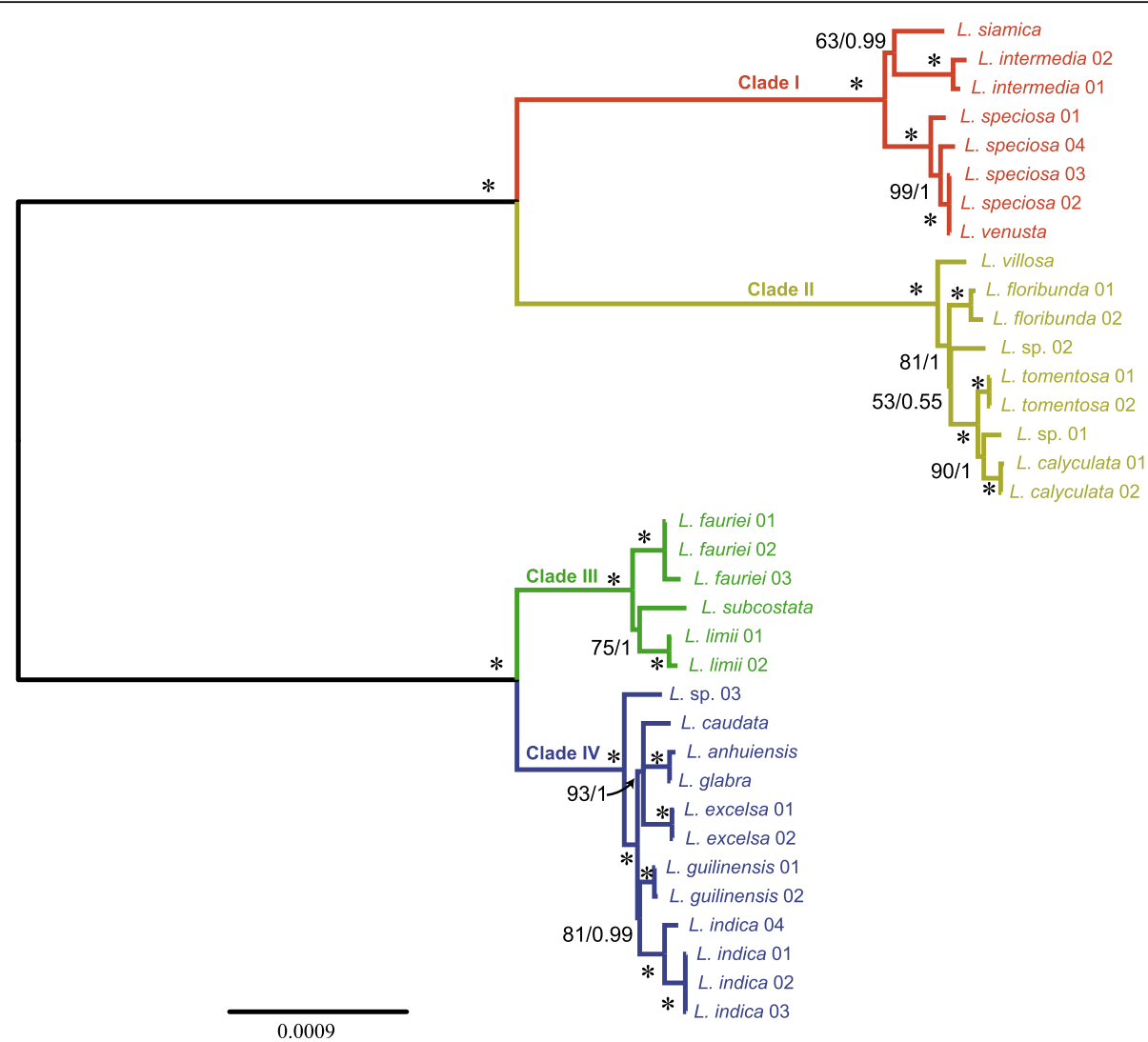

Fig. 4 Molecular phylogeny of Lagerstroemia resulting from $\mathrm{ML}$ and $\mathrm{BI}$ analyses using whole chloroplast genome sequences (dataset-3). Maximum likelihood bootstrap values (BS) and posterior probabilities (PP) are shown at nodes. Branches with * indicate $100 \%$ BS and a PP of 1.0

In clade I, $L$. venusta was a hexaploid species [11] and fell within the L. speciosa phylogenetically (Figs. 3 and 4). We inferred that $L$. venusta might be an allohexaploid species and its female parent was $L$. speciosa. The branch length was short in most terminal nodes, which showed Lagerstroemia may be undergone a rapid radiation [30, 31]. The phylogenomics of Myrtales based on 66 protein-coding genes showed the 14 Lagerstroemia species formed four clades [17]. However, the relationship of Lagerstroemia was inconsistent with this study. The difference might be caused by the longer branch length of $L$. intermedia [17] which affected the topology of the phylogenetic tree. We used the same dataset to infer a similar tree as this study. Further investigations, including extended sampling, more morphological analysis and additional nuclear markers, are needed to insight the evolution of Lagerstroemia.

\section{Divergence time of Lagerstroemia}

The fossil record of the Lagerstroemia consists of leaf impressions, wood, and pollen [18]. According to the fossil record, the oldest confirmed evidence of the Lagerstroemia is a leaf impression of $L$. patelii from India, which was dated as early Eocene or late Paleocene/Thanetian in age $(\sim 56 \mathrm{Ma})[32,33]$. The oldest occurrence of accepted Lagerstroemia pollen is from the middle Eocene of Central Java [34]. Those records indicated the origin time of Lagerstroemia was earlier than $56 \mathrm{Ma}$. Our data also support a late Paleocene origin ( $60 \mathrm{Ma}$, Fig. 5; Table 2).

There were a number of putative fossil Lagerstroemia leaves and wood in the middle Miocene [18]. For example, the leaf species of $L$. mioparviflora, L. eomicrocarpa and L. siwalica were described from Nepal [35, 36], and L. jamraniensis was from the Kathgodam area [37]. The wood fossil record of Lagerstroemia is used as the form genus Lagerstroemioxylon Mädler. The wood is recorded from Sumatra (Lagerstroemioxylon eoflosreginum)[38] and Myanmar (Lagerstroemioxylon irrawaddiensis) [39] and is widely encountered in India at several localities (Lagerstroemioxylon arcotense, Lagerstroemioxylon deomaliensis, Lagerstroemioxylon eoflosreginum) [18, 40]. Those fossil records suggest that Lagerstroemia was common and somewhat diverse in the wet subtropical forests of the Indian subcontinent in the middle Miocene. The phylogeny and dating analyses 


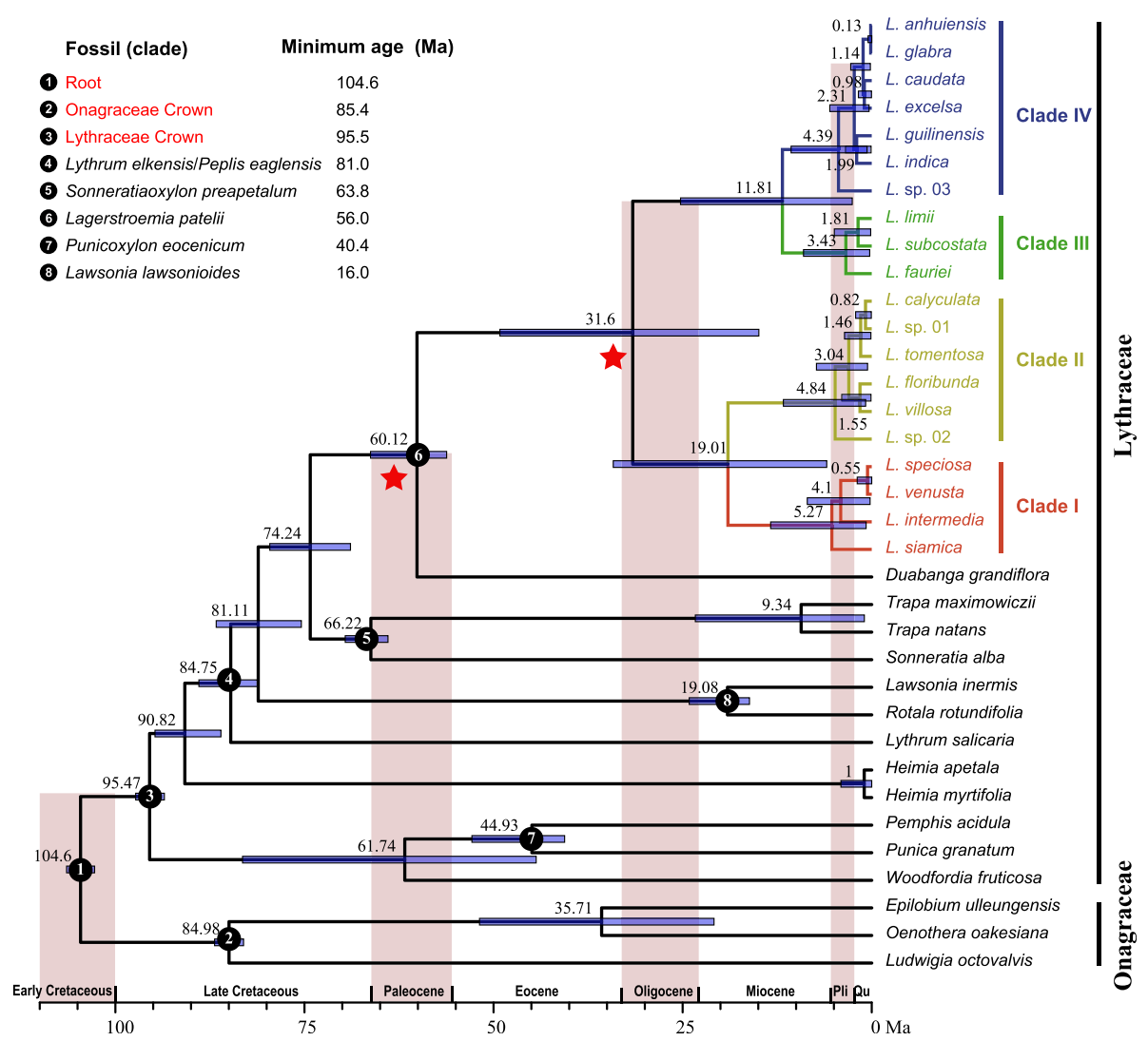

Fig. 5 Maximum clade credibility (MCC) tree of Lythraceae obtained from BEAST analysis. Mean divergence time estimates are shown with 95\% highest posterior density (HPD; blue bars). Black circles indicate the eight calibration points

demonstrate a similar pattern of this genus divergence into four clades during the Miocene $\sim 20$ Ma. Diversification with Lagerstroemia occurred in the Pleistocene $5.3 \mathrm{Ma}$, and at this time, this genus is present and persists in Japan $[18,41]$.

\section{Conclusions}

In this study, we report 20 newly sequenced chloroplast genomes of the genus Lagerstroemia. The overall genomic structure, including gene number and gene order, was well-conserved. The relationship and divergence times of Lagerstroemia were revealed using complete chloroplast genome sequence data. Four clades were found in this genus. Greater taxon sampling is necessary to determine the number of species, morphological characteristics, evolution and biogeography. Our study showed that the chloroplast genome data will provide adequate information for resolving the phylogenetic relationships in this difficult-to-characterize genus.

\section{Methods}

Plant materials, genomic DNA extraction and sequencing According to the morphological classification, the Lagerstroemia was classified into four sections and eight subsections [1]. In order to infer the framework of the phylogenetic relationship, we sampled 20 individuals of 17 described species, which represented all the four sections and six of eight subsections. The materials were obtained from the field, botanical gardens and the herbarium of the Institute of Botany, Chinese Academy of Sciences (PE, Table S1). Three crape myrtle samples could not be accurately identified morphologically because of the lack of morphological characters. In addition to the newly collected material for DNA sequencing, publicly available complete chloroplast genome sequences (15 accessions, Table S1) of Lagerstroemia were also included in this analysis.

Total genomic DNA was extracted from silica-dried leave tissues of living plants and herbarium specimens of this genus following the modified CTAB DNA extraction protocol [42]. The DNA from silica-dried tissue was fragmented to construct 350-bp insert libraries, and the DNA from the herbarium material was constructed using 150-bp insert libraries according to the manufacturer's manual (Illumina Inc., San Diego, CA, USA) and was then used for sequencing. Paired-end sequencing was performed on an Illumina HiSeq X-ten at Novogene in Tianjin, China, yielding 
approximately $4 \mathrm{~Gb}$ of high-quality 150 -bp paired-end reads per sample.

\section{Chloroplast genome assembly, annotation, and comparative analyses}

A four-step approach was employed to assemble the chloroplast genome. First, adaptors were removed, and low-quality sequences were trimmed using Trimmomatic 0.39 [43] with the following parameters: LEAD ING $=20$, TRAILING $=20$, SLIDINGWINDOW $=4: 15$, MINLEN $=36$ and AVGQUAL $=20$. Second, remaining high-quality reads were assembled de novo into contigs using SPAdes 3.6.1 [44]. Third, chloroplast genome sequence contigs were selected from the initial assembly by performing a BLAST search using the L. subcostata chloroplast genome sequence as a reference (GenBank accession number: KF572029). The selected contigs from chloroplast genomes were further assembled using Sequencher 5.4 .5 (http://www.genecodes.com). Fourth, Geneious 11.1.2 was used to map all reads to the assembled chloroplast genome sequence to check the four junctions between the inverted repeats (IRs) and the small single-copy (SSC)/large single-copy (LSC) regions.

Chloroplast genome sequences were annotated using Plann [45] and, missing or incorrect genes were checked in Sequin. Physical maps of the circular chloroplast genomes were visualized with OGDRAW [46]. To assess sequence divergence and to explore highly variable chloroplast markers, nucleotide diversity $(\pi)$ was calculated by sliding window analysis using DnaSP v6 [47], and nucleotide substitutions and p-distance were calculated using MEGA 7.0 [48].

\section{Alignment and data matrix construction}

The sequence alignments were constructed with MAFF $\mathrm{T}$ v7 [49]. All alignments were visually inspected with MEGA 7.0 [48] and manually adjusted where needed. To access the phylogenetic effects of the different regions in the chloroplast genome, we created six datasets based on different chloroplast genome regions or using different outgroups. All 78 protein-coding genes and four rRNA genes were extracted from the GenBankformatted files containing all chloroplast genomes using Python scripts. Those 82 genes were combined into a concatenated dataset as dataset-1. Dataset- 2 included 35 whole chloroplast genome sequences of Lagerstroemia and five other species of Lythraceae as outgroups (Lythrum salicaria, Lawsonia inermis, Rotala rotundifolia, Sonneratia alba, and Duabanga grandiflora). Ambiguous alignment regions were trimmed using Gblocks 0.91b [50] implemented in Phylosuite v1.1 [51]. In addition, the third to sixth datasets only included 35 samples of Lagerstroemia, which were from the complete chloroplast genomes, LSC region, IR region, and SSC region, respectively.

\section{Phylogenetic analyses}

We used maximum likelihood (ML) and Bayesian inference (BI) methods for phylogenetic analyses. The datasets were unpartitioned, and the best-fit model was determined by ModelFinder [52]. Maximum likelihood analyses were run with RAxML v.8.1.24 [53]. RAxML searches were made with 500 randomized maximum parsimony starting trees, and RAxML was run again under the same conditions executing 1,000 nonparametric bootstrap replicates to assess the branch support.

BI was run with Mrbayes v3.2 [54]. Two independent Markov Chain Monte Carlo (MCMC) analyses were performed, each with four chains (three heated and one cold) for 20 million generations with sampling of every 100th tree. Each chain started with a random tree, and the first $25 \%$ sampled generations were discarded as burn-in to construct a majority-rule consensus tree and to estimate posterior probabilities (PP). Stationarity was considered to be reached when the average standard deviation of split frequencies was $<0.01$.

\section{Fossil priors and BEAST analyses}

We used BEAST v2.5.1 [55] to estimate the divergence times using dataset-1 and added seven Lythraceae species and three Onagraceae species to accommodate all available fossil calibrations. This dataset was calibrated using five reliably dated fossils. The pollen of Lythrum elkensis Grimsson et al./Peplis eaglensis Grimsson et al. was recently described from the Late Cretaceous early Campanian (82-81 Ma) Eagle Formation at Elk Basin, Wyoming, USA [18]. This fossilized pollen was used to offset for the crown of the two lineages. Sonneratiaoxylon preapetalum Awasthi was fossil wood of Sonneratia [56] from the early Paleocene of India (Danian, 67.3$63.8 \mathrm{Ma}$ ) and was used to calibrate the most recent common ancestor (TMRCA) of Sonneratia and Trapa to > 63.8 Ma. We also used the oldest fossil accepted as Punica, which was wood of Punicoxylon eocenicum Privé-Gill from the middle Eocene (48.6-40.4 Ma) of Paris [18], and the seed of Lawsonia lawsonioides (Menzel) Mai. [57] from the middle Miocene (16 Ma ago) as conservative offsets on the stem nodes of Punica and Lawsonia, respectively. The oldest confirmed fossil of Lagerstroemia patelii Lakhanpal \& Guleria, from the late Paleocene/Eocene (ca. $56 \mathrm{Ma}$ ) was used to calibrate the stem age of this genus to $>56 \mathrm{Ma}[18,58]$. Each of the five fossil priors (Lythrum elkensis/Peplis eaglensis, Sonneratiaoxylon preapetalum, Punicoxylon eocenicum, Lawsonia lawsonioides, and Lagerstroemia patelii) was given a lognormal distribution with offset values as specified (i.e., 81.0, 63.8, 40.4, 16.0, and $56.0 \mathrm{Ma}$, 
respectively), and with a mean of 1.5 and a standard deviation of 1 , allowing for the possibility that these nodes are considerably older than the fossils themselves. In addition to these fossil priors, we also used three secondary priors. Based on the average value obtained by Berger et al. [59] in a calibrated analysis, three priors were used: (1) the average age of TMRCA of Lythraceae and Onagraceae (the root of the tree) was 104.6 Ma; (2) the crown age of Onagraceae was 85.4 Ma; and (3) the crown age of Lythraceae was $95.5 \mathrm{Ma}$. Each secondary prior was placed under normal distribution with a standard deviation of 1 .

To assess possible calibration incongruence, we ran twelve analyses with calibration combinations (Table 2). The twelve analyses were run with uncorrelated lognormal distribution (UCLD) relaxed molecular clock models to account for rate variability among lineages, the Yule speciation model and 100,000,000 generations with the MCMC method, sampling trees every 10,000 generations. The stationary phase was examined through Tracer 1.6 [60] to evaluate convergence and to ensure sufficient and effective sample size (ESS) for all parameters surpassing 200. A burnin of $10 \%$ generations was discarded, and TreeAnnotator v2.4.7 was used to produce a Maximum Clade Credibility tree.

\section{Abbreviations}

BI: Bayesian Inference; bp: Base pairs; Gb: Gigabases; LSC: Long single copy; Ma: Million years ago; MCMC: Markov chain Monte Carlo; ML: Maximum likelihood; NCBI: National Center for Biotechnology Information; NGS: Next generation sequencing; $\pi$ : Nucleotide diversity; rRNA: Ribosomal RNA; SSC: Short single copy; SSR: Simple sequence repeat; tRNA: Transfer RNA

\section{Supplementary Information}

The online version contains supplementary material available at https://doi. org/10.1186/s12864-021-07769-x

Additional file 1: Table S1. Taxa included in the present study. Collection locality and voucher information are provided for newly sequenced samples.

Additional file 2: Figure S1. ML tree for Lagerstroemia using combined three universal plant DNA barcodes and four highly variable regions.

Additional file 3: Figure S2. Molecular phylogeny of Lagerstroemia resulting from ML (maximum likelihood) and BI (Bayesian inference) analyses using LSC regions (dataset-4). Maximum likelihood bootstrap values (BS) and posterior probabilities (PP) are shown at nodes. Branches with * indicate $100 \%$ BS and a PP of 1.0.

Additional file 4: Figure S3. Molecular phylogeny of Lagerstroemia resulting from ML (maximum likelihood) and BI (Bayesian inference) analyses using IR regions (dataset-5). Maximum likelihood bootstrap values (BS) and posterior probabilities (PP) are shown at nodes. Branches with * indicate $100 \% \mathrm{BS}$ and a PP of 1.0 .

Additional file 5: Figure S4. Molecular phylogeny of Lagerstroemia resulting from ML (maximum likelihood) and BI (Bayesian inference) analyses using SSC regions (dataset-6). Maximum likelihood bootstrap values (BS) and posterior probabilities (PP) are shown at nodes. Branches with * indicate $100 \% \mathrm{BS}$ and a PP of 1.0 .

\section{Acknowledgements}

The authors thank Boxing Hou, Cuihua Gu, Xiaobai Jin, Jin Chen, Shouzhou Zhang, Jun-jie Yu, Zulin Ning, Bingqiang Xu, Huijin Zhang, Kaihong He, Zhirong Yang, and Ruili Li for their advice and kind help in the field investigation and sample collection. The authors thank the Plant DNA Bank of China in the Institute of Botany, Chinese Academy of Sciences for providing materials.

\section{Authors' contributions}

WD and ZS planned the projects, designed the research, analyzed data, and wrote the manuscript. WD, CX and YL performed the experiments, and analyzed data. JS and WL provided samples, contributed ideas, collected and analyzed the data. All authors have read and approved the manuscript.

\section{Funding}

This study was financially supported by the National Natural Science Foundation of China (No. 31770744), the Fundamental Research Funds for the Central Universities (NO. BLX201932), and the National Forest Genetic Resources Platform (2005DKA21003).

\section{Availability of data and materials}

The chloroplast genome of Lagerstroemia under study is deposited in the GenBank database under the following accession numbers: MT019844 MT019863. The other sequences used in this study were downloaded from the NCBI.

\section{Declarations}

Ethics approval and consent to participate Not applicable.

\section{Consent for publication}

Not applicable.

\section{Competing interests}

The authors declare that they have no competing interests.

\section{Author details}

'Laboratory of Systematic Evolution and Biogeography of Woody Plants, School of Ecology and Nature Conservation, Beijing Forestry University, 100083 Beijing, China. ${ }^{2}$ State Key Laboratory of Systematic and Evolutionary Botany, Institute of Botany, Chinese Academy of Sciences, 100093 Beijing, China. ${ }^{3}$ University of Chinese Academy of Sciences, 100049 Beijing, China. ${ }^{4}$ Xishuangbanna Tropical Botanical Garden, Chinese Academy of Sciences, Mengla 666303, China. Institute of Forestry New Technologies, Chinese Academy of Forestry, 100091 Beijing, China.

Received: 24 August 2020 Accepted: 3 June 2021

Published online: 09 June 2021

\section{References}

1. Furtado C, Srisuko M. A revision of Lagerstroemia L.(Lythraceae). Gardens Bull. 1969;24:185-334.

2. De Wilde WJJO, Duyfjes BEE. Survey of Lagerstroemia L. (Lythraceae) in Indochina (excl. Thailand) with the description of Lagerstroemia densiflora, sp nov., a new species from Vietnam. Adansonia. 2016;38(2):241-55.

3. Qin HN, Graham S: Lagerstroemia. In: Flora of China. vol. 13. Beijing: Science Press; Miss. Bot. Gard. Press; 2007:277-281.

4. Cai M, Pan H-T, Wang $X-F$, He D, Wang $X-Y$, Wang $X-J$, Zhang $Q-X$. Development of novel microsatellites in Lagerstroemia indica and DNA fingerprinting in Chinese Lagerstroemia cultivars. Sci Hortic. 2011;131:88-94.

5. De Wilde WJ, Duyfjes BE. Miscellaneous information on Lagerstroemia L. (Lythraceae). Thai Forest Bull (Botany). 2013;41:90-101.

6. De Wilde W, Duyfjes B. Lagerstroemia (Lythraceae) in Malesia. Blumea. 2014; 59(2):113-22.

7. Pham $T$, Tagane $S$, Chhang $P$, Yahara $T$, Souradeth $P$, Nguyen $T$. Lagerstroemia ruffordii (Lythraceae), a new species from Vietnam and Cambodia. Acta Phytotaxonom Geobotan. 2017;68(3):175-80.

8. Shi S, Huang Y, Tan F, He X, Boufford DE. Phylogenetic analysis of the Sonneratiaceae and its relationship to Lythraceae based on ITS sequences of nrDNA. J Plant Res. 2000;113(3):253-8. 
9. Graham SA, Hall J, Sytsma K, Shi Sh. Phylogenetic analysis of the Lythraceae based on four gene regions and morphology. Int J Plant Sci. 2005;166(6): 995-1017.

10. Suo Z, Li W, Jin $X$, Zhang $H$. A new nuclear DNA marker revealing both microsatellite variations and single nucleotide polymorphic loci: a case study on classification of cultivars in Lagerstroemia indica L. J Micro Biochem Tech. 2016:8:266-71.

11. Liu Y. Ploidy determination in Lagerstroemia L. using flow cytometry and its polymorphism of cpDNA. Zhengzhou: Henan Agricultural University; 2010.

12. Dong W, Xu C, Wu P, Cheng T, Yu J, Zhou S, Hong D-Y. Resolving the systematic positions of enigmatic taxa: Manipulating the chloroplast genome data of Saxifragales. Mol Phylogenet Evol. 2018;126:321-30.

13. Dong W, Xu C, Li W, Xie X, Lu Y, Liu Y, Jin X, Suo Z. Phylogenetic resolution in Juglans based on complete chloroplast genomes and nuclear DNA sequences. Front Plant Sci. 2017:8:1148.

14. Dong W, Xu C, Wen J, Zhou S. Evolutionary directions of single nucleotide substitutions and structural mutations in the chloroplast genomes of the family Calycanthaceae. BMC Evol Biol. 2020;20(1):96.

15. Xu C, Dong W, Li W, Lu Y, Xie X, Jin X, Shi J, He K, Suo Z. Comparative analysis of six Lagerstroemia complete chloroplast genomes. Front Plant Sci. 2017;8(15):15

16. Gu C, Tembrock LR, Johnson NG, Simmons MP, Wu Z. The complete plastid genome of Lagerstroemia fauriei and loss of rp/2 intron from Lagerstroemia (Lythraceae). PLOS ONE. 2016;11(3):e0150752.

17. Gu C, Ma L, Wu Z, Chen K, Wang Y. Comparative analyses of chloroplast genomes from 22 Lythraceae species: inferences for phylogenetic relationships and genome evolution within Myrtales. BMC Plant Biol. 2019; 19(1):281.

18. Graham SA. Fossil records in the Lythraceae. Bot Rev. 2013;79(1):48-145.

19. Shaw J, Lickey EB, Schilling EE, Small RL. Comparison of whole chloroplast genome sequences to choose noncoding regions for phylogenetic studies in angiosperms: the tortoise and the hare III. Am J Bot. 2007:94(3):275-88.

20. Dong W, Liu J, Yu J, Wang L, Zhou S. Highly variable chloroplast markers for evaluating plant phylogeny at low taxonomic levels and for DNA barcoding. PLOS ONE. 2012;7(4):e35071.

21. Dong W, Xu C, Li C, Sun J, Zuo Y, Shi S, Cheng T, Guo J, Zhou S. ycf1, the most promising plastid DNA barcode of land plants. Sci Rep. 2015;5:8348.

22. Huang YL, Shi SH. Phylogenetics of Lythraceae sensu lato: A preliminary analysis based on chloroplast $r b c L$ gene, psaA-ycf3 spacer, and nuclear rDNA internal transcribed spacer (ITS) sequences. Int J Plant Sci. 2002;163(2):21525.

23. Liu Y, He D, Cai M, Tang W, Li XY, Pan HT, Zhang QX. Development of microsatellite markers for Lagerstroemia indica (Lythraceae) and related species. Appl Plant Sci. 2013;1(2):1200203.

24. Sancho R, Cantalapiedra CP, Lopez-Alvarez D, Gordon SP, Vogel JP, Catalan P, Contreras-Moreira B. Comparative plastome genomics and phylogenomics of Brachypodium: flowering time signatures, introgression and recombination in recently diverged ecotypes. New Phytol. 2018;218(4):1631-44.

25. Wang $Y-H$, Wicke $S$, Wang H, Jin J-J, Chen S-Y, Zhang S-D, Li D-Z, Yi T-S. Plastid genome evolution in the early-diverging Legume subfamily Cercidoideae (Fabaceae). Front Plant Sci. 2018;9:138.

26. Lloyd Evans D, Joshi SV, Wang J. Whole chloroplast genome and gene locus phylogenies reveal the taxonomic placement and relationship of Tripidium (Panicoideae: Andropogoneae) to sugarcane. BMC Evol Biol. 2019;19(1):33.

27. Yang X-Y, Wang Z-F, Luo W-C, Guo X-Y, Zhang C-H, Liu J-Q, Ren G-P. Plastomes of Betulaceae and phylogenetic implications. J Syst Evol. 2019; 57(5):508-18.

28. Zhang $X$, Deng T, Moore MJ, Ji Y, Lin N, Zhang H, Meng A, Wang H, Sun Y Sun H. Plastome phylogenomics of Saussurea (Asteraceae: Cardueae). BMC Plant Biol. 2019;19(1):290

29. Wang M, Wang X, Sun J, Wang Y, Ge Y, Dong W, Yuan Q, Huang L. Phylogenomic and evolutionary dynamics of inverted repeats across Angelica plastomes. BMC Plant Biol. 2021;21(1):26.

30. Barrett CF, Baker WJ, Comer JR, Conran JG, Lahmeyer SC, Leebens-Mack JH, Li J, Lim GS, Mayfield-Jones DR, Perez L, et al. Plastid genomes reveal support for deep phylogenetic relationships and extensive rate variation among palms and other commelinid monocots. New Phytol. 2016;209(2): $855-70$

31. Ma PF, Zhang YX, Zeng CX, Guo ZH, Li DZ. Chloroplast phylogenomic analyses resolve deep-level relationships of an intractable bamboo tribe Arundinarieae (Poaceae). Syst Biol. 2014;63(6):933-50.
32. Lakhanpal R, Guleria J, Awasthi N. The fossil floras of Kachchh. III- Tertiary megafossils. Palaeobotanist. 1984;33:228-319.

33. Biswas S. Tertiary stratigraphy of Kutch. J Palaeontol Soc India. 1992;37:1-29.

34. Morley RJ. Origin and evolution of tropical rain forests. Chichester: John Wiley \& Sons; 2000.

35. Dwivedi $H$, Prasad M, Tripathi P. Fossil leaves belonging to the family Fabaceae and Lythraceae from Siwalik sediments of Koilabas area, western Nepal. Geophytology. 2006;36(1-2):113-21.

36. Prasad M. Plant megafossils from the Siwalik sediments of Koilabas, central Himalaya, Nepal and their impact on palaeoenvironment. Phytomorphology. 1994;44:115-26.

37. Prasad M, Ghosh R, Tripathi P. Floristics and climate during Siwalik (Middle Miocene) near Kathgodam in the Himalayan foot-hills of Uttranchal, India. J Palaeontol Soc India. 2004;49:35-93.

38. Kramer K. Die tertiären Hölzer Südost-Asiens (unter Ausschluß der Dipterocarpaceae) Palaeontographica Abteilung B 1974:1-150.

39. Prakash U, Vaidyanathan L, Tripathi P. Plant remains from the Tipam sandstones of northeast India with remarks on the palaeoecology of the region during the Miocene. Palaeontographica Abteilung B. 1994;231:11346

40. Mehrotra R, Liu X-Q, Li C-S, Wang Y-F, Chauhan M. Comparison of the Tertiary flora of southwest China and northeast India and its significance in the antiquity of the modern Himalayan flora. Rev Palaeobot Palynol. 2005; 135(3-4):145-63.

41. Momohara A. A plant macrofossil assemblage from the Kiyokawa Formation in the Shimousa Group and reconstruction of the palaeoclimate based on it. Quatern Res. 2006:45:211-6.

42. Li J, Wang S, Jing Y, Wang L, Zhou S. A modified CTAB protocol for plant DNA extraction. Chin Bull Bot. 2013:48(1):72-8.

43. Bolger AM, Lohse M, Usadel B. Trimmomatic: a flexible trimmer for Illumina sequence data. Bioinformatics. 2014;30(15):2114-20.

44. Bankevich A, Nurk S, Antipov D, Gurevich AA, Dvorkin M, Kulikov AS, Lesin VM, Nikolenko SI, Pham S, Prjibelski AD, et al. SPAdes: a new genome assembly algorithm and its applications to single-cell sequencing. J Comput Biol. 2012;19(5):455-77.

45. Huang DI, Cronk QCB. Plann: A command-line application for annotating plastome sequences. Appl Plant Sci. 2015;3(8):1500026.

46. Greiner S, Lehwark P, Bock R. OrganellarGenomeDRAW (OGDRAW) version 1 3.1: expanded toolkit for the graphical visualization of organellar genomes. Nucleic Acids Res. 2019;47(W1):W59-64

47. Rozas J, Ferrer-Mata A, Sanchez-DelBarrio JC, Guirao-Rico S, Librado P, Ramos-Onsins SE, Sanchez-Gracia A. DnaSP 6: DNA sequence polymorphism analysis of large data sets. Mol Biol Evol. 2017;34(12): 3299-302.

48. Kumar S, Stecher G, Tamura K: MEGA7: Molecular Evolutionary Genetics Analysis Version 7.0 for Bigger Datasets. Mol Biol Evol. 2016;33(7):18701874.

49. Katoh K, Standley DM. MAFFT multiple sequence alignment software version 7: improvements in performance and usability. Mol Biol Evol. 2013; 30(4):772-80.

50. Castresana J. Selection of conserved blocks from multiple alignments for their use in phylogenetic analysis. Mol Biol Evol. 2000;17(4):540-52.

51. Zhang D, Gao F, Jakovlic I, Zou H, Zhang J, Li WX, Wang GT. PhyloSuite: An integrated and scalable desktop platform for streamlined molecular sequence data management and evolutionary phylogenetics studies. Mol Ecol Res. 2020;20(1):348-55.

52. Kalyaanamoorthy $S$, Minh BQ, Wong TKF, von Haeseler A, Jermiin LS. ModelFinder: fast model selection for accurate phylogenetic estimates. Nat Methods. 2017:14(6):587-9.

53. Stamatakis A. RAxML version 8: a tool for phylogenetic analysis and postanalysis of large phylogenies. Bioinformatics. 2014;30(9):1312-3.

54. Ronquist F, Teslenko M, van der Mark P, Ayres DL, Darling A, Hohna S, Larget B, Liu L, Suchard MA, Huelsenbeck JP. MrBayes 3.2: efficient Bayesian phylogenetic inference and model choice across a large model space. Syst Biol. 2012;61(3):539-42.

55. Bouckaert R, Heled J, Kuhnert D, Vaughan T, Wu CH, Xie D, Suchard MA, Rambaut A, Drummond AJ. BEAST 2: a software platform for Bayesian evolutionary analysis. PLoS Comput Biol. 2014;10(4): e1003537.

56. Awasthi N. A fossil wood of Sonneratia from the Tertiary of South India. Palaeobotanist. 1968;17:254-7. 
57. Mai DH. Zwei neue Arten von Samen aus dem deutschen Jungtertiär. Feddes Repertorium. 1996;107(5-6):299-303.

58. Lakhanpal R, Prakash U, Awasthi N. Some more dicotyledonous woods from the Tertiary of Deomali, Arunachal Pradesh, India. Palaeobotanist. 1981;27(3): 232-52.

59. Berger BA, Kriebel R, Spalink D, Sytsma KJ. Divergence times, historical biogeography, and shifts in speciation rates of Myrtales. Mol Phylogenet Evol. 2016;95:116-36.

60. Rambaut A, Suchard M, Xie D, Drummond A: Tracer v1. 6. 2014: Available from http://beast.bio.ed.ac.uk/Tracer.

\section{Publisher's Note}

Springer Nature remains neutral with regard to jurisdictional claims in published maps and institutional affiliations.

- fast, convenient online submission

- thorough peer review by experienced researchers in your field

- rapid publication on acceptance

- support for research data, including large and complex data types

- gold Open Access which fosters wider collaboration and increased citations

- maximum visibility for your research: over $100 \mathrm{M}$ website views per year

At BMC, research is always in progress. 